\title{
Comparison of the long-term cause of failure and survivorship of four hundred and twenty seven metal-on-metal hip arthroplasties: resurfacing versus large head total hip arthroplasty
}

\author{
Michele Palazzuolo $^{1} \cdot$ Alexander Antoniadis $^{1}$ (D) $\cdot$ Leilani Delaune $^{1} \cdot$ Inès Tornare $^{1} \cdot J_{\text {Jlien }}$ Wegrzyn $^{1}$
}

Received: 5 February 2021 / Accepted: 12 April 2021 / Published online: 21 June 2021

(c) The Author(s) 2021

\begin{abstract}
Introduction Comparison of mid- to long-term cause of failure and survivorship of metal-on-metal (MoM) resurfacing hip arthroplasty (RHA) and large head total hip arthroplasty (THA) remains sparse. This study aimed to identify and compare the cause of failure and survivorship of MoM RHA and THA at a minimum ten year follow-up.

Methods Four hundred twenty-seven MoM hip arthroplasties (286 THA and 141 RHA) were retrospectively analyzed at a mean follow-up of $13 \pm$ three years. Causes of failure were reported as MoM specific (i.e., adverse reaction to metal debris (ARMD) and painful hip with ion elevation) or MoM non-specific (i.e., fracture, infection, and dislocation). Chromium (Cr) and cobalt (Co) ion levels and $\mathrm{Co} / \mathrm{Cr}$ ratio were compared. Survivorship was compared according to the cause of failure with revision as the endpoint.

Results The rate of ARMD was significantly higher in THA (OR=2.9 [95\%-CI: $1-7] ; p=0.02)$. No significant difference was detected in failure rate due to other causes between the two groups $(p=0.2-0.9)$. Ion levels and $\mathrm{Co} / \mathrm{Cr}$ ratio were both significantly higher in THA $(p<0.01)$. Survivorship was significantly lower in THA compared to RHA at ten years [89\% (95\%-CI: 85\%-91\%) vs $96 \%$ (95\%-CI: 91\%-98\%); $p=0.01$ ] and 15 years [73\% (95\%-CI: 67\%-78\%) vs 83\% (95\%-CI: 73\%-90\%); $p=0.01]$.

Conclusion RHA survivorship was significantly higher at any time point. Failure rate due to ARMD was significantly higher in THA while no significant difference in other causes of failure was observed between the two groups. This result emphasizes the role of fretting corrosion at the head-neck junction (i.e., trunnionosis) with significantly higher ion levels and $\mathrm{Co} / \mathrm{Cr}$ ratio dissociation in THA.
\end{abstract}

Keywords Metal-on-metal bearing $\cdot$ Total hip arthroplasty $\cdot$ Hip resurfacing $\cdot$ Complication $\cdot$ Survivorship $\cdot$ Trunnionosis

\section{Introduction}

Large head metal-on-metal (MoM) total hip arthroplasty (THA) regained popularity in the last decade of the twentieth century after the introduction of modern resurfacing hip arthroplasty (RHA). MoM bearing surfaces were postulated at that time to decrease the risk of aseptic loosening related to wear and therefore to increase implant survivorship compared to conventional metal or ceramic on polyethylene bearings [1]. However, several reports in the literature raised safety concerns about MoM

Alexander Antoniadis

alexander.antoniadis@chuv.ch

1 Department of Orthopedic Surgery, Lausanne

University Hospital - CHUV, Avenue Pierre-Decker, 4,

CH-1011 Lausanne, Switzerland bearing due to increased chromium (Cr) and cobalt (Co) blood ion concentrations [2-5], adverse reaction to metal debris (ARMD) [6-8], osteolysis [9], and implant loosening [10-13], leading to restriction of use imposed by regulatory agencies worldwide. To date, the outcome of MoM THA is known to be poorer than conventional bearings with complication rates as high as $15.5 \%$ at ten years $[14,15]$. Conversely, the outcome of RHA was reported to be more favourable at mid- to longterm follow-up with survivorship ranging from 91 to $99.7 \%$ at ten years $[16,17]$. Therefore, such differences in survivorship have raised questions about different modes of failure between these two MoM hip arthroplasties that could explain better longterm survivorship achieved with RHA.

However, clinical series comparing the cause of failure and survivorship between MoM THA and RHA at midterm follow-up remain sparse [18-20] and are even lacking with consistent long-term follow-up. To our knowledge, 
only the study of Ridon et al. [15] compared the midterm outcome of the same MoM bearing between THA and RHA. This study suggested the role of trunnionosis to explain the higher ion elevation and rate of failure due to ARMD in MoM THA compared to RHA [15]. However, this study included a limited number of patients with a mean follow-up of less than 10 years. Therefore, the current single-center and retrospective study on prospectively collected data aimed to identify and compare the failure mode and survivorship of MoM THA and RHA at a minimum ten year follow-up with a particular attention to specific complications related to the MoM bearing.

\section{Patients and methods}

\section{Patients and procedures}

Between 1998 and 2010, a continuous series of $474 \mathrm{MoM}$ hip arthroplasties (413 patients, 322 THA and 152 RHA) were prospectively included in our institutional total joint registry and retrospectively analyzed at the latest follow-up (Fig. 1). The patient's informed consent and Institutional Review Board approval were obtained before initiating this study (CER-VD \#2019-02,172). All the procedures were performed in patients $<75$ years with advanced hip OA excluding inflammatory, traumatic, oncologic, and septic indications. The other exclusion criteria were known allergy to metal, kidney failure, and women with childbearing potential. The implant used was Birmingham Hip Resurfacing $®$ (Smith \& Nephew, London, UK) for RHA and Durom ${ }^{\circledR}$ cup construct with Metasul ${ }^{\circledR}$ Large Diameter Head and CLS/Spotorno® stem (Zimmer, Warsaw, IN, USA) for THA. The median head diameter for THA was $46 \pm 4 \mathrm{~mm}$ and $48 \pm 4 \mathrm{~mm}$ for RHA. All the procedures were performed through a conventional posterolateral approach by or under the direct supervision of a single senior fellowship-trained hip arthroplasty surgeon at our institution.

At the latest follow-up evaluation, six patients (5\%) in the RHA group and 19 patients (7\%) were lost to follow-up.

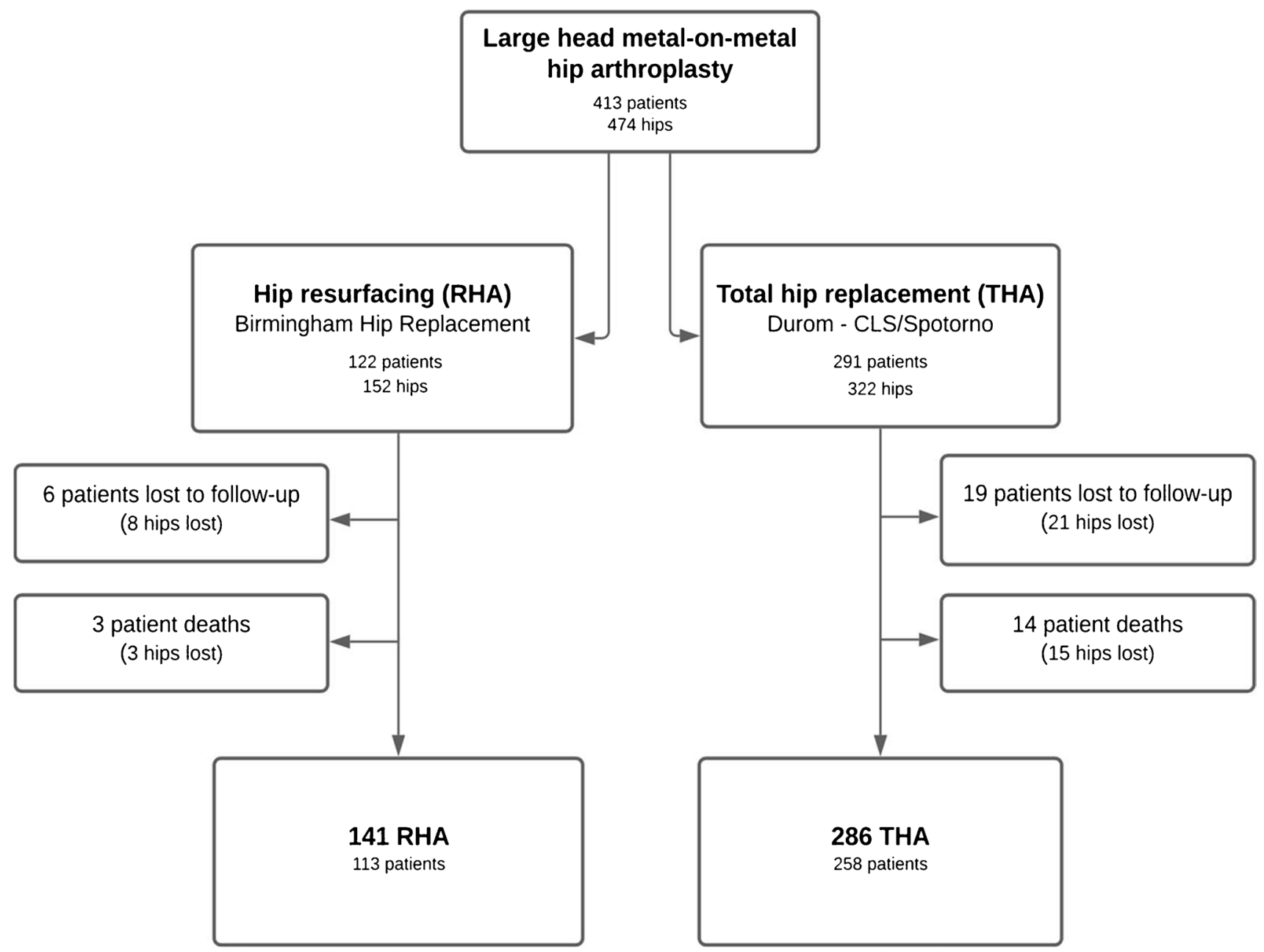

Fig. 1 Study flowchart 
In addition, three patients (2\%) in the RHA group and 19 patients (5\%) in the THA group were deceased (Fig. 1). Therefore, 427 MoM hip arthroplasties including 141 RHA and 286 THA were analyzed at a mean follow-up of $13 \pm$ three years (range: 10 to 19 years). There were 241 women $(65 \%)$ and 130 men (35\%) with a mean age at surgery of $55 \pm 13$ years for THA and of $51 \pm$ nine years for RHA $(p=0.01)$.

\section{Evaluation}

Patients returned for post-operative follow-up visits at three months, six months, one year, and annually thereafter. Patients underwent an annual clinical examination, and plain antero-posterior and lateral radiographs of the pelvis and the operated-on hip were obtained. Blood ion measurements were performed. Patients who did not attend the annual visit were contacted by phone. Cobalt $(\mathrm{Co})$ and chromium $(\mathrm{Cr})$ ion blood levels were measured according to international standards [21]. All the patients with ion values above $119 \mathrm{nmol} / \mathrm{l}$ for cobalt and $135 \mathrm{nmol} / \mathrm{l}$ for chromium and/or painful hip underwent metal artifact reduction sequence magnetic resonance imaging (MARS-MRI) to evaluate potential adverse reaction to metal debris (ARMD) to the hip [22].

At the latest follow-up, the data from our institutional joint registry were analyzed to identify the cases which underwent revision surgery. Then, the causes of failure in the MoM RHA and THA groups were analyzed through retrospective chart review and reported as MoM specific (i.e., ARMD and painful hip with ion elevation) or MoM nonspecific (i.e., periprosthetic fracture, infection, dislocation). In accordance with the recommendations of Swiss Orthopaedics [23], patients with painful hip associated with blood ion levels above $340 \mathrm{nmol} / \mathrm{l}$ for cobalt and $386 \mathrm{nmol} / \mathrm{l}$ for chromium underwent revision even in the absence of ARMD on the MARS-MRI evaluation. The revision was defined as the exchange of either one of the components or all of them. Revision for any reason was considered as the endpoint for survivorship analysis.

\section{Statistical analysis}

An a priori power analysis was performed to confirm that this study is adequately powered. Indeed, the total sample size to be included was 280 patients to detect a significant difference in survivorship between the two groups with a significance level of 0.05 and a power of 0.8 .

Quantitative variables are presented as mean \pm standard deviation. Comparison of continuous and quantitative variables between the two groups was performed using twosample $t$-tests. Comparison of qualitative variables between the two groups was performed using Fisher's exact tests. Survivorship analyses were performed using Kaplan-Meier curves with $95 \%$ confidence intervals $(95 \%$-CI) at 5, 10, and 15 years using RHA or THA revision for any cause as the endpoint. Comparative survivorship analyses between the two groups were performed according to the cause of failure (i.e., MoM specific or non-specific) using log-rank tests. A linear regression model was applied to detect a possible correlation between head diameter and specific metal-on-metal failure causes for both THA and RHA. Statistical analyses were performed using the SPSS version 22 software (SPSS Inc, Chicago, IL) with a level of significance set at $p<0.05$.

\section{Results}

\section{Modes of failure}

At a mean follow-up of $13 \pm$ three years, the overall rate of failure was $20 \%(56 / 286$ hips) in THA and $11 \%(16 / 141$ hips) in RHA ( $p=0.03)$ (Table 1).

\section{MoM specific}

The most common cause of failure of THA was ARMD (33/56 THA, 59\%), whereas the main cause of failure of RHA was painful hip with ion elevation (7/16 RHA, 44\%) (Table 1). Failure due to ARMD was significantly higher in THA than in RHA (33 THA [59\%] vs 6 RHA [38\%], $p=0.02$; OR 2.93, 95\%-CI: 1.2-7.2). No significant difference was detected in the failure rate due to painful hip with ion elevation $(p=0.8)$ (Table 1$)$. In addition, no significant correlation was detected between femoral head size and MoM-specific modes of failure in a linear regression model for both THA and RHA $\left(R^{2}=0.098\right.$ and $R^{2}=0.094$, respectively).

Table 1 Causes of failure of metal-on-metal (MoM) resurfacing (RHA) and large head total hip arthroplasty (THA)

\begin{tabular}{llll}
\hline & THA & RHA & \\
\hline MoM specific & $\underline{\mathrm{N}(\%)}$ & $\underline{\mathrm{N}(\%)}$ & p-value \\
ARMD & & & \\
Pain & $33(59)$ & $6(38)$ & 0.02 \\
MoM non-specific & $12(21)$ & $7(44)$ & 0.80 \\
Fracture & & & \\
Infection & $3(5)$ & $2(12)$ & 0.67 \\
Instability & $6(11)$ & $0(0)$ & 0.18 \\
Total & $2(4)$ & $1(6)$ & $>0.99$ \\
\hline
\end{tabular}




\section{MoM non-specific}

The most common cause of failure of large head MoM THA was infection (6/56 THA, 11\%), while the main cause of failure of MoM RHA was periprosthetic femoral neck fracture (2/16 RHA, 12\%) (Table 1). No significant difference was detected in the failure rate due to MoM non-specific causes between the two groups ( $p=0.2$ to 0.9 , Table 1$)$.

\section{Co and $\mathrm{Cr}$ ions}

At the latest follow-up, the Co level was significantly higher in THA compared to RHA $(53 \pm 94 \mathrm{nmol} / \mathrm{L}$ vs $26 \pm 78 \mathrm{nmol} / \mathrm{L} ; p<0.001$ ) (Fig. 2). No significant difference was detected in $\mathrm{Cr}$ level between THA and RHA $(44 \pm 73 \mathrm{nmol} / \mathrm{L}$ vs $41 \pm 56 \mathrm{nmol} / \mathrm{L} ; p=0.3)$ (Fig. 2). The $\mathrm{Co} / \mathrm{Cr}$ ratio was significantly higher in THA compared to RHA $(1.78 \pm 1.82$ vs $0.94 \pm 0.63 ; p<0.0001)$ (Fig. 3 ).

\section{Survivorship}

Overall survivorship was significantly higher in RHA compared to THA at 5 years (98\% [95\%-CI: $94 \%-99 \%$ ] vs 96\% [95\%-CI: 94\%-98\%]; $p=0.01)$, ten years (96\% [95\%CI: $91 \%-98 \%$ ] vs $89 \%$ [95\%-CI: $85 \%-91 \%$ ]; $p=0.01$ ),
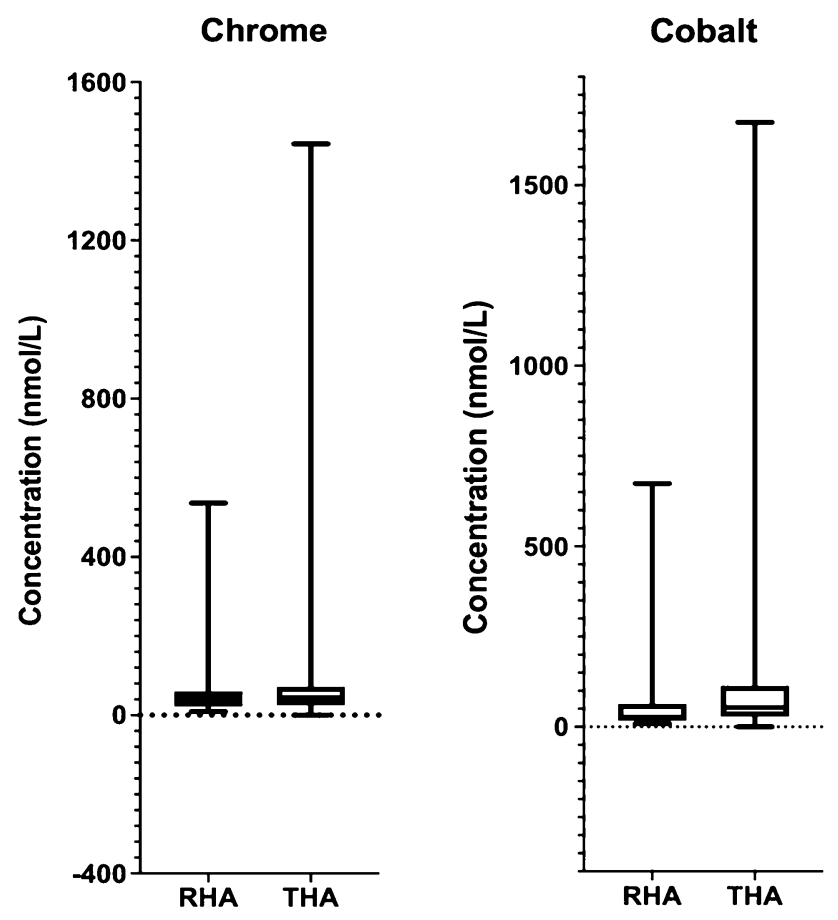

Fig. 2 Chrome and cobalt ion level in metal-on-metal resurfacing (RHA) and large head total hip arthroplasty (THA)
Fig. 3 Cobalt/chrome ratio in metal-on-metal resurfacing (RHA) and large head total hip arthroplasty (THA) 67\%-78\%]; $p=0.01$ ) (Fig. 4).

Survivorship related to MoM-specific causes of failure was significantly higher in RHA compared to THA at five years (99\% [CI 95\%-99\%] vs 98\% [CI 96\%-99\%]; $p=0.02)$, ten years (98\% [CI 93\%-99\%] vs 90\% [CI $88 \%-93 \%$ ]; $p=0.02)$, and 15 years $(85 \%$ [CI 75\%-91\%] vs $76 \%$ [CI 70\%-80\%]; $p=0.02$ ) (Fig. 5).

No significant difference was detected in survivorship related to MoM non-specific causes of failure between the two groups at five, ten or 15 years ( $p=0.3$ ) (Fig. 6).

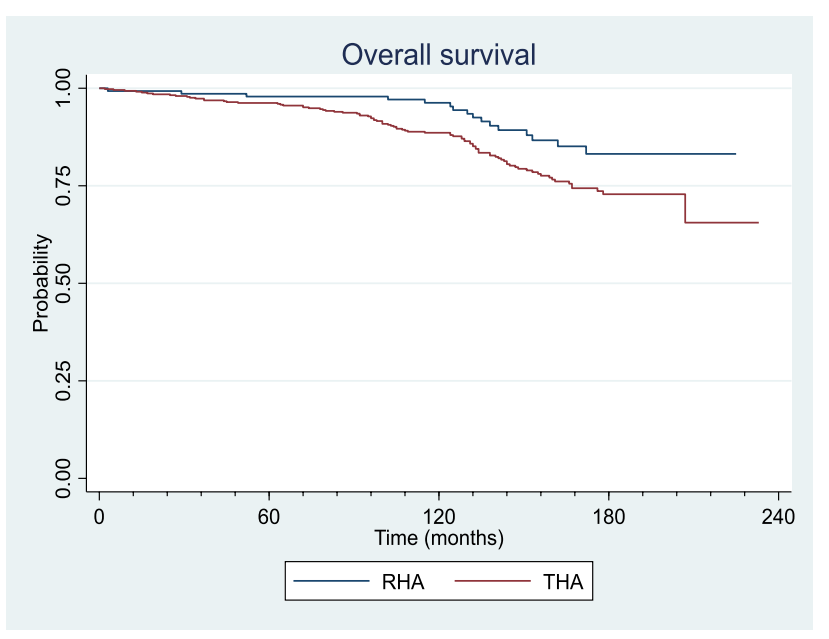

Fig. 4 Overall survivorship curves for metal-on-metal resurfacing (RHA) and large head total hip arthroplasty (THA) 


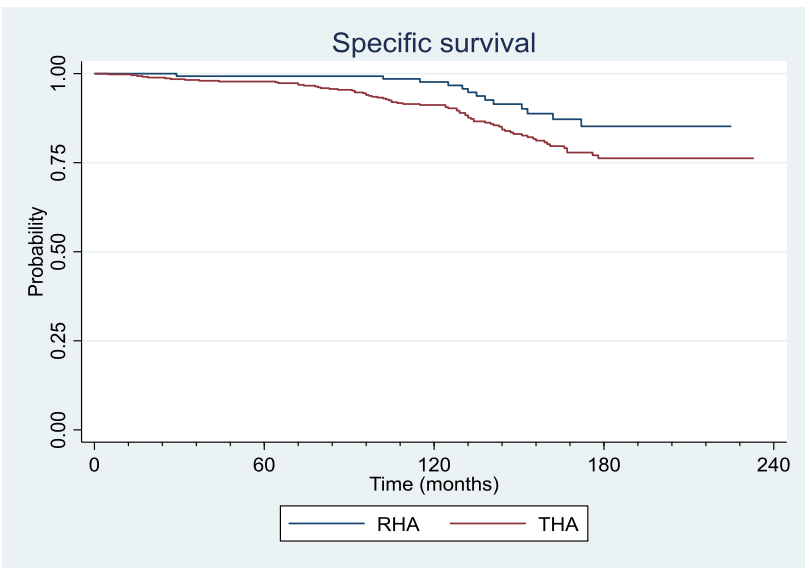

Fig. 5 Survivorship curves for metal-on-metal specific cause of failure for resurfacing (RHA) and large head total hip arthroplasty (THA)

\section{Discussion}

MoM bearing remains controversial in RHA and has been largely abandoned in THA due to early catastrophic failures such as ARMD associated with potential major bone loss and severe damages to the soft tissue at the time of revision [24, 25]. Conversely, RHA is still performed in some centers and reported with excellent functional outcome and survivorship up to $99.7 \%$ at 10 years $[16,26]$. However, series that compared survivorship of MoM RHA and large head THA with consistent long-term follow-up are lacking. Therefore, this study aimed to identify and compare the mode of failure and survivorship of RHA and THA at a minimum ten year follow-up with a particular attention to

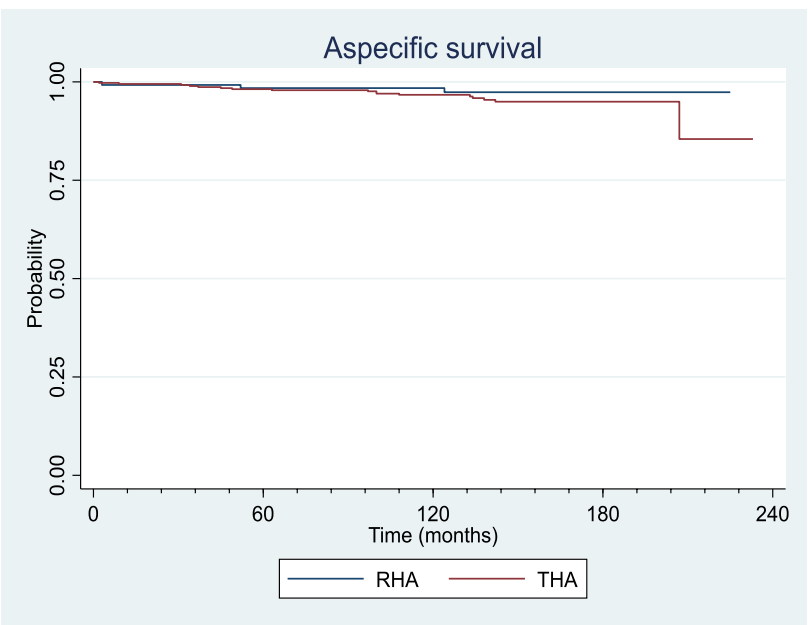

Fig. 6 Survivorship curves for metal-on-metal non-specific cause of failure for resurfacing (RHA) and large head total hip arthroplasty (THA) specific complications related to MoM bearing. The most important finding of the present study was that survivorship of RHA was significantly higher than survivorship of large head MoM THA at five, ten and 15 years after surgery. Importantly, this difference in survivorship was explained by a 2.93-fold increase in failure rate due to ARMD in THA. Indeed, ion levels and dissociation of $\mathrm{Co} / \mathrm{Cr}$ ratio were significantly higher in THA. Therefore, these results emphasize the potential role of trunnionosis as the main mechanism of failure in THA and not only the MoM bearing by itself.

The overall 15 -year survivorship of $83 \%$ in RHA and $73 \%$ in THA observed in the current study was in agreement with the previous series [15, 27-35]. Indeed, $\mathrm{Ng}$ et al. and Althuizen et al. reported a high failure rate for Durom ${ }^{\circledR}$ MoM THA with a ten year revision rate ranging from 14 to $31 \%$ [36, 37]. In our series, Co level and $\mathrm{Co} / \mathrm{Cr}$ ratio were significantly higher in THA compared to RHA. These findings suggest an additional source of ion production in THA other than the head-cup bearing interface $[4,38,39]$. A similar result was described by Ridon et al. and Johnson et al. in series comparing RHA and THA constructs performed with the same acetabular component $[15,40]$. In addition, Garbuz et al. showed that patients with a large head MoM THA presented with a 46-fold and tenfold increase in Co and $\mathrm{Cr}$ levels respectively compared to RHA [18]. Goldberg et al. demonstrated that $\mathrm{Cr}$ release remains localized around the taper of the femoral stem, while Co is released into the blood, leading to a higher blood level of $\mathrm{Co}$ and dissociation of the $\mathrm{Co} / \mathrm{Cr}$ ratio in THA [38]. Therefore, this $\mathrm{Co} / \mathrm{Cr}$ ratio dissociation could be supposed to be a direct consequence of fretting corrosion (i.e., trunnionosis) at the head-neck junction. Moreover, trunnionosis was also described as the result of a local interplay between the head/taper engagement levels, and the horizontal lever arm and load offset applied on the trunnion [41-43]. Consequently, the contribution of trunnionosis to metal ion production and ARMD could be considered as a natural phenomenon in large head MoM THA that is not influenced by implant positioning or edge loading at the MoM bearing level [43]. Therefore, we believe that ion production at the Morse taper interface could explain the significantly higher incidence of ARMD and lower implant survivorship in the THA group of the current study. In addition, the metal debris production due to trunnionosis might increase third body wear at the MoM bearing interface and therefore increase the risk of ARMD in THA [43]. By definition, RHA is not affected by potential trunnionosis. This could explain the significantly lower ion levels and ARMD rate, and higher survivorship compared to THA we observed in the current long-term follow-up study. Taking altogether, these results suggest that RHA may be a valid bone preserving option in carefully selected patients [16]. Our study presented with some limitations. First, this total joint registry study was observational and 
focused on revision rate and survivorship. This study did not aim to evaluate functional or radiological outcomes. Second, the indication for a RHA or THA procedure was at the senior surgeon's discretion, with RHA mainly performed in younger and more active patients presenting with primary hip osteoarthritis. Therefore, the two groups were not matched for age, sex, patient's functional demand, or indication. Third, no analysis of the implants was performed after RHA or THA revision. Especially, no trunnion analysis such as tribo-corrosion was performed on the explanted femoral stem neck and head. Only gross macroscopic assessment of the trunnion was mentioned in operative reports.

\section{Conclusion}

Survivorship of MoM hip arthroplasty was significantly higher in RHA than in THA at any time point. Failure rate due to ARMD was significantly higher in THA, while no significant difference in the other causes of failure was observed between the two groups. Along with significantly higher ion levels and $\mathrm{Co} / \mathrm{Cr}$ ratio dissociation, this result emphasized the potential role of fretting corrosion at the head-neck junction in THA. Therefore, aside from the MoM bearing itself, trunnionosis might significantly contribute to the higher rate of ARMD and poorer survivorship in THA compared to RHA.

Author contributions All the authors have made substantial contributions to conception and design, or acquisition of data, or analysis and interpretation of data; have been involved in drafting the manuscript or revising it critically for important intellectual content; have given final approval of the version to be published; and agree to be accountable for all aspects of the work in ensuring that questions related to the accuracy or integrity of any part of the work are appropriately investigated and resolved.

Funding Open Access funding provided by Université de Lausanne.

Data availability All the data and material are saved in an anonymized repository file folder and available upon request.

\section{Declarations}

Ethical approval The patient's informed consent and Institutional Review Board approval were obtained before initiating this study (CER-VD \#2019-02,172).

Conflict of interest The authors declare no competing interests.

Open Access This article is licensed under a Creative Commons Attribution 4.0 International License, which permits use, sharing, adaptation, distribution and reproduction in any medium or format, as long as you give appropriate credit to the original author(s) and the source, provide a link to the Creative Commons licence, and indicate if changes were made. The images or other third party material in this article are included in the article's Creative Commons licence, unless indicated otherwise in a credit line to the material. If material is not included in the article's Creative Commons licence and your intended use is not permitted by statutory regulation or exceeds the permitted use, you will need to obtain permission directly from the copyright holder. To view a copy of this licence, visit http://creativecommons.org/licenses/by/4.0/.

\section{References}

1. Fisher J, Jin Z, Tipper J, et al (2006) Presidential guest lecture: tribology of alternative bearings. In: Clinical Orthopaedics and Related Research. Lippincott Williams and Wilkins, pp 25-34

2. Granchi D, Savarino LM, Ciapetti G, Baldini N (2018) Biological effects of metal degradation in hip arthroplasties. Crit Rev Toxicol 48:170-193. https://doi.org/10.1080/10408444.2017.1392927

3. Amanatullah DF, Sucher MG, Bonadurer GF et al (2016) Metal in total hip arthroplasty: wear particles, biology, and diagnosis. Orthopedics 39:371-379. https://doi.org/10.3928/0147744720160719-06

4. Ohtsuru T, Morita Y, Murata Y et al (2017) Blood metal ion concentrations in metal-on-metal total hip arthroplasty. Eur J Orthop Surg Traumatol 27:527-532. https://doi.org/10.1007/ s00590-017-1931-y

5. Daniel J, Ziaee H, Pradhan C, McMinn DJW (2009) Six-year results of a prospective study of metal ion levels in young patients with metal-on-metal hip resurfacings. J Bone Jt Surg - Ser B 91:176-179. https://doi.org/10.1302/0301-620X.91B2.21654

6. Haddad FS, Thakrar RR, Hart AJ et al (2011) Metal-on-metal bearings: the evidence so far. J Bone JtSurg - Ser B 93 B:572579. https://doi.org/10.1302/0301-620X.93B4.26429

7. Canham CD, Muradov PI, Simpson JB, Incavo SJ (2017) Corrosion and adverse local tissue reaction after total hip arthroplasty with a modular titanium alloy femoral neck. Arthroplast Today 3:211-214. https://doi.org/10.1016/j.artd.2017.03.003

8. Kwon YM, Thomas P, Summer B et al (2010) Lymphocyte proliferation responses in patients with pseudotumors following metalon-metal hip resurfacing arthroplasty. J Orthop Res 28:444-450. https://doi.org/10.1002/jor.21015

9. Park YS, Moon YW, Lim SJ et al (2005) Early osteolysis following second-generation metal-on-metal hip replacement. J Bone Jt Surg - Ser A 87:1515-1521. https://doi.org/10.2106/JBJS.D.02641

10. Jacobs JJ, Hallab NJ (2006) Loosening and osteolysis associated with metal-on-metal bearings: a local effect of metal hypersensitivity? J Bone Jt Surg - Ser A 88:1171-1172. https://doi.org/10. 2106/JBJS.F.00453

11. Chen SY, Chang CH, Hu CC et al (2016) Metal ion concentrations and semen quality in patients undergoing hip arthroplasty: a prospective comparison between metal-on-metal and metal-onpolyethylene implants. J Orthop Res 34:544-551. https://doi.org/ 10.1002/jor.23037

12. Bala A, Penrose CT, Seyler TM et al (2016) Is metal-on-metal total hip arthroplasty associated with neurotoxicity? J Arthroplasty 31:233-236.e1. https://doi.org/10.1016/j.arth.2016.03.035

13. Tharani R, Dorey FJ, Schmalzried TP (2001) The risk of cancer following total hip or knee arthroplasty. J Bone Jt Surg - Ser A 83:774-780. https://doi.org/10.2106/00004623-200105000-00019

14. Wiley KF, Ding K, Stoner JA et al (2013) Incidence of pseudotumor and acute lymphocytic vasculitis associated lesion (ALVAL) reactions in metal-on-metal hip articulations: a meta-analysis. J Arthroplasty 28:1238-1245. https://doi.org/10.1016/j.arth.2013.03.027

15. Ridon PE, Putman S, Migaud H et al (2019) Long-term comparative study of large-diameter metal-on-metal bearings: resurfacing 
versus total arthroplasty with large-diameter Durom ${ }^{\mathrm{TM}}$ bearing. Orthop Traumatol Surg Res 105:943-948. https://doi.org/10. 1016/j.otsr.2019.04.006

16. Girard J (2017) Hip resurfacing: international perspectives: Review Article. HSS J 13:7-11

17. Hunter TJA, Moores TS, Morley D et al (2018) 10-year results of the Birmingham Hip Resurfacing: a non-designer case series. HIP Int 28:50-52. https://doi.org/10.5301/hipint.5000518

18. Garbuz DS, Tanzer M, Greidanus NV et al (2010) The john charnley award: metal-on-metal hip resurfacing versus large-diameter head metal-on-metal total hip arthroplasty: a randomized clinical trial. Clin Orthop Relat Res 468:318-325. https://doi.org/10.1007/ s11999-009-1029-x

19. Beaulé PE, Kim PR, Hamdi A, Fazekas A (2011) A prospective metal ion study of large-head metal-on-metal bearing: a matchedpair analysis of hip resurfacing versus total hip replacement. Orthop Clin North Am 42:251-257. https://doi.org/10.1016/j. ocl.2011.01.005

20. Vendittoli PA, Lavigne M, Roy AG, Lusignan D (2006) A prospective randomized clinical trial comparing metal-on-metal total hip arthroplasty and metal-on-metal total hip resurfacing in patients less than 65 years old. HIP Int 16. https://doi.org/10.5301/ hip. 2008.1446

21. Sidaginamale RP, Joyce TJ, Lord JK et al (2013) Blood metal ion testing is an effective screening tool to identify poorly performing metal-on-metal bearing surfaces. Bone Joint Res 2:84-95. https:// doi.org/10.1302/2046-3758.25.2000148

22. Connelly JW, Galea VP, Matuszak SJ et al (2018) Indications for MARS-MRI in patients treated with metal-on-metal hip resurfacing arthroplasty. J Arthroplasty 33:1919-1925. https://doi.org/10. 1016/j.arth.2018.01.024

23. Guyen O, Tissot C (2016) Suivi des patients avec arthroplastie de hanche métal-métal et stratégie de prise en charge des complications. Rev Med Suisse 12:2156-2163

24. Pijls BG, Meessen JMTA, Tucker K et al (2019) MoM total hip replacements in Europe: a NORE report. EFORT Open Rev 4:423-429. https://doi.org/10.1302/2058-5241.4.180078

25. Crawford DA, Adams JB, Morris MJ et al (2019) Revision of failed metal-on-metal total hip arthroplasty: midterm outcomes of 203 consecutive cases. J Arthroplasty 34:1755-1760. https:// doi.org/10.1016/j.arth.2019.04.019

26. Ortiz-Declet VR, Iacobelli DA, Yuen LC et al (2017) Birmingham Hip Resurfacing vs total hip arthroplasty: a matched-pair comparison of clinical outcomes. J Arthroplasty 32:3647-3651. https:// doi.org/10.1016/j.arth.2017.06.030

27. Goronzy J, Stiehler M, Kirschner S, Günther KP (2010) Durom $^{\mathrm{TM}}$-Hüftober-flächenersatz Kurz- bis mittelfristiges radiologisches und klinisches ergebnisse. Orthopade 39:842-852. https://doi.org/10.1007/s00132-010-1656-7

28. Naal FD, Pilz R, Munzinger U et al (2011) High revision rate at 5 years after hip resurfacing with the durom implant. Clin Orthop Relat Res 469:2598-2604. https://doi.org/10.1007/ s11999-011-1792-3

29. Leclercq S, Lavigne M, Girard J et al (2013) Durom hip resurfacing system: retrospective study of 644 cases with an average follow-up of 34 months. Orthop Traumatol Surg Res 99:273-279. https://doi.org/10.1016/j.otsr.2012.10.018

30. Robinson PG, Wilkinson AJ, Meek RMD (2014) Metal ion levels and revision rates in metal-on-metal hip resurfacing arthroplasty: a comparative study. HIP Int 24:123-128. https://doi.org/10.5301/ hipint.5000113

31. Scholes CJ, Ebrahimi M, Farah SB et al (2019) The outcome and survival of metal-on-metal hip resurfacing in patients aged less than 50 years. A prospective observational cohort study with minimum ten-year follow-up. Bone Jt J 101B:113-120. https:// doi.org/10.1302/0301-620X.101B1.BJJ-2018-0702.R1

32. Saragaglia D, Belvisi B, Rubens-Duval B et al (2015) Clinical and radiological outcomes with the Durom ${ }^{\mathrm{TM}}$ acetabular cup for large-diameter total hip arthroplasty: 177implants after a mean of 80months. Orthop Traumatol Surg Res 101:437-441. https://doi. org/10.1016/j.otsr.2015.02.008

33. Lardanchet JF, Taviaux J, Arnalsteen D et al (2012) One-year prospective comparative study of three large-diameter metal-onmetal total hip prostheses: serum metal ion levels and clinical outcomes. Orthop Traumatol Surg Res 98:265-274. https://doi. org/10.1016/j.otsr.2011.11.009

34. Ras Sørensen S-AL, Jørgensen HL, Sporing SL, Lauritzen JB (2016) Revision rates for metal-on-metal hip resurfacing and metal-on-metal total hip arthroplasty - a systematic review. Hip Int 26:515-521. https://doi.org/10.5301/hipint.5000444

35. Long WT, Dastane M, Harris MJ et al (2010) Failure of the durom metasul® acetabular component. Clin Orthop Relat Res 468:400_ 405. https://doi.org/10.1007/s11999-009-1071-8

36. Ng VY, Arnott L, McShane MA (2011) Perspectives in managing an implant recall: revision of 94 durom metasul acetabular components. J Bone Jt Surg - Ser A 93:5-9. https://doi.org/10.2106/ JBJS.J.01311

37. Althuizen MNR, Hooff ML v, Saskia HM v d Berg-v Erp, et al (2012) Early failures in large head metal-on-metal total hip arthroplasty. HIP Int 22:641-647. https://doi.org/10.5301/HIP.2012. 10340

38. Goldberg JR, Gilbert JL, Jacobs JJ, et al (2002) A multicenter retrieval study of the taper interfaces of modular hip prostheses. Clin Orthop Relat Res 149-61

39. Lainiala OS, Moilanen TPS, Hart AJ et al (2016) Higher blood cobalt and chromium levels in patients with unilateral metal-onmetal total hip arthroplasties compared to hip resurfacings. J Arthroplasty 31:1261-1266. https://doi.org/10.1016/j.arth.2015. 11.045

40. Johnson AJ, Le Duff MJ, Yoon JP et al (2013) Metal ion levels in total hip arthroplasty versus hip resurfacing. J Arthroplasty 28:1235-1237. https://doi.org/10.1016/j.arth.2013.03.015

41. Hothi HS, Eskelinen AP, Berber R et al (2017) Factors associated with trunnionosis in the metal-on-metal pinnacle hip. J Arthroplasty 32:286-290. https://doi.org/10.1016/j.arth.2016.06.038

42. Pereira X, Moga I, Harrington MA, et al Variables influencing tribo-corrosion of modular junctions in metal-on-polyethylene THR

43. Weiser MC, Lavernia CJ (2017) Trunnionosis in total hip arthroplasty. J Bone Jt Surg - Am 99:1489-1501. https://doi.org/10. 2106/JBJS.17.00345

Publisher's Note Springer Nature remains neutral with regard to jurisdictional claims in published maps and institutional affiliations. 